\title{
Endarterectomy for Asymptomatic Carotid Stenosis in the Real World
}

Can. J. Neurol. Sci. 2000; 27: 95-96

Studies of carotid endarterectomy (CE) in the United States ${ }^{1}$ and more recently in $\mathrm{Canada}^{2}$ showing that up to $67 \%$ of procedures were either of uncertain value or inappropriate suggest that case selection is of critical importance. The major clinical decision to make in cases of carotid stenosis is whether to operate upon those with asymptomatic disease. This problem can be considered with the aid of an efficacy $\rightarrow$ effectiveness cycle. The steps are as follows:

1. Proof of efficacy (outcome of randomized clinical trials (RCTs));

2. Development of clinical practice guidelines (CPGs);

3. Knowledge and beliefs of practitioners;

4. Actions of practitioners;

5. Measurement of effectiveness (real world outcomes);

6. Comparison of effectiveness with efficacy. In reality, these steps are often not consecutive.

The paper by Chaturvedi et $\mathrm{al}^{3}$ in this issue of the journal (see page 116) sheds light on steps 3 and 4 .

The best evidence of efficacy (step 1) for CE in asymptomatic carotid stenosis (ACS) is from the Asymptomatic Carotid Atherosclerosis Study (ASAS) ${ }^{4}$ which found that CE produced an absolute risk reduction (ARR) of $1.5 \%$ over 2 years, ${ }^{5}$ yielding a number needed to treat (NNT) of 67 CEs to prevent one stroke in two years. This was based on a very low peri-operative death and/or stroke $(\mathrm{M} / \mathrm{M})$ rate of $2.3 \%$. The American Heart Association $^{6}$ produced a CPG (step 2) stating that ACS was a suitable indication for CE provided that the peri-operative $\mathrm{M} / \mathrm{M}$ rate was $\leq 3.0 \%$. Conversely, the Canadian Stroke Consortium ${ }^{7}$ recommended against $\mathrm{CE}$ for ACS and the Canadian Neurosurgical Society ${ }^{8}$ CPG put it in the uncertain category.

Peri-operative stroke and/or death rate in recent asymptomatic carotid stenosis clinical stenosis

$\begin{array}{lrl} & \mathrm{n} & \text { M/M Rate } \\ \text { Hartmann '99 } & 54 & 5.6 \% \\ \text { Kucey '98 } & 350 & 4.0 \% \\ \text { Cebul '98 } & 322 & 2.5 \% \\ \text { Karp '98 } & 1002 & 3.0 \% \\ \text { Wong '97 } & 117 & 5.2 \% \\ \text { Bratzler'96 } & 350 & 3.7 \% \\ \text { Total Cases } & 2195 & \chi=3.5 \%(2.6,4.2)\end{array}$

In this issue of the journal, the knowledge, beliefs and practices of Canadian and American neurologists were surveyed (steps 3 and 4). Unfortunately, only two knowledge questions were asked. Few neurologists knew that ACAS did not show that CE for ACS prevented disabling strokes. Over $80 \%$ of neurologists believed that the $\mathrm{M} / \mathrm{M}$ rate for CE for ACS at their hospitals was $<3 \%$. What is the real $\mathrm{M} / \mathrm{M}$ in clinical practice? The table shows the results from six recently published series of cases from North America ${ }^{9-12}$ and Germany. ${ }^{13}$ Only one study found an $\mathrm{M} / \mathrm{M}$ rate $<3 \%$ and the overall mean was 3.5\% (2.6,
4.2, 95\% CI). This suggests that the surveyed neurologists are likely unaware of the true complication rates for $\mathrm{CE}$ at their hospitals, rates which are likely higher than 3\% in most cases. Nevertheless, more than half the American neurologists said that they sometimes/often refer cases for CE, although only $11 \%$ of Canadians said so (step 4).

Step 5 in the cycle is to measure the real world effectiveness, a difficult proposition, since stroke prevention, the desired outcome, is inevitably delayed. However, an estimate of this can be made using a sensitivity analysis of outcome of CE for ACS based on the ACAS results which had a $\mathrm{M} / \mathrm{M}$ of $2.3 \%$. If the real world peri-operative $\mathrm{M} / \mathrm{M}$ is $3.5 \%$, as it was in these recent case series, the ARR would be $0.3 \%(-0.6,1.0,95 \% \mathrm{CI})$. This would yield an NNT of 333 CEs to prevent one stroke over two years. Also, since the $95 \%$ confidence limits for the ARR include zero, one cannot conclude that CE for ACS has any net value in stroke prevention.

The last step in the cycle is the comparison of this estimate of effectiveness with the efficacy results from the ACAS study. In this case, the promise of CE for ACS has not been realized in the real world, at least in the recent studies cited. Effectiveness (in this case the ARR) may sometimes be as high as efficacy, as shown in a recent study of thrombolysis for acute stroke, ${ }^{14}$ but it is usually lower, and must be measured to determine the real value of treatment interventions and how to improve them in clinical practice settings. Finally, CPGs must be consistent and based on a complete analysis of the evidence, both from RCTs and clinical practice, if they are to have validity and usefulness.

Thomas E. Feasby Calgary, Alberta

\section{REFERENCES}

1. Winslow C, Solomon D, Chassin M, et al. The appropriateness of carotid endarterectomy. New Eng J Med 1988;318:721-727.

2. Wong J, Findlay J, Suarez-Almazor M. Regional performance of carotid endarterectomy. Appropriateness, outcomes and risk factors for complications. Stroke 1997;228:891-898.

3. Chaturvedi S, Meinke JL, St. Pierre E, Bertasio B. Attitudes of Canadian and U.S neurologists regarding carotid endarterectomy for asymptomatic stenosis. Can J Neurol Sci 2000;27(3):116-119.

4. Executive Committee for the Asymptomatic Carotid Atherosclerosis Study. Endarterectomy for asymptomatic carotid artery stenosis. JAMA1995;273:1421-1428.

5, Barnett HJM, Eliaziw M, Meldrum H, Taylor D. Do the facts and figures warrant a 10-fold increase in the performance of carotid endarterectomy on asymptomatic patients? Neurology 1996;46:603-608.

6. Biller J, Feinberg WM, Castaldo JE, et al. Guidelines for carotid endarterectomy: a statement for healthcare professionals from a special writing group of the Stroke Council, American Heart Association. Circulation 1998;97:501-509.

7. Perry JR, Szalai JP, Norris JW. Consensus against both endarterectomy and routine screening for asymptomatic carotid artery stenosis. Arch Neurol 1997;54:25-28. 
8. Findlay JM, Tucker WS, Ferguson GG, et al. Guidelines for the use of carotid endarterectomy: current recommendations from the Canadian Neurosurgical Society. Can Med Assoc J 1997; 157:653-659.

9. Kucey DS, Bowyer B, Iron K, et al. Determinants of outcome after carotid endarterectomy. J Vasc Surg 1998;28:1051-1058.

10. Bratzler DW, Oehlert W, Murray C, et al. Carotid endarterectomy in Oklahoma Medicare beneficiaries: patient characteristics and outcomes. J Okla St Med Assoc 1996;89:423-429.

11. Karp HR, Flanders D, Shipp CC, et al. Carotid endarterectomy among Medicare beneficiaries. A statewide evaluation of appropriateness and outcome. Stroke 1998;29:46-52.

12. Cebul RD, Snow JR, Pine R, et al. Indications, outcomes, and provider volumes for carotid endarterectomy. JAMA 1998;279:1282-1287.

13. Hartmann A, Hupp T, Koch H, et al. Prospective study on the complication rate of carotid surgery. Cerebrovascular Diseases 1999;9:152-156.

14. Buchan AM, Barber PA, Newcommon N, et al. Effectiveness of tPA in acute ischemic stroke: outcome relates to appropriateness. Neurology 2000;54:679-687. 